\title{
sciendo
}

\section{Match Performance Indicators that Discriminated Between Winning, Drawing and Losing Teams in the 2017 AFCON Soccer Championship}

\author{
by \\ Alliance Kubayi ${ }^{1}$, Abel Toriola ${ }^{1}$
}

\begin{abstract}
The purpose of this study was to examine match performance indicators that discriminated between winning, drawing and losing teams in the 2017 Total Africa Cup of Nations (AFCON) soccer championship. Data were collected from 32 matches during the AFCON soccer tournament using the InStat ${ }^{\circledR}$ system. The studied variables included the number of goals scored, the time period in which a goal was scored and the impact of the first goal on the match outcome, as well as total shots, shots on goal, total passes, accurate passes, corners, ball possession, fouls, offsides as well as yellow and red cards. The results showed that goals scored (1.80 \pm 0.83$)$, total shots (11.05 \pm 4.83$)$, shots on target $(4.70 \pm 2.62)$, fouls $(18.60 \pm 5.19)$, offsides $(2.35 \pm 1.76)$, yellow cards $(1.55 \pm 1.10)$, and red cards $(0.05 \pm 0.22)$ were discriminative performance indicators of winning teams. In contrast, losing teams yielded higher mean values in total passes $(260.30 \pm 49.10)$, accurate passes $(69.28 \pm 5.74)$, corners $(5.10 \pm 2.95)$, and ball possession (51.20 \pm 5.52$)$. In conclusion, these results have practical implications for coaches in planning and implementing team tactics for successful performance.
\end{abstract}

Key words: performance, game-related statistics, goals, team sports.

\section{Introduction}

The Africa Cup of Nations (AFCON) is the main continental soccer competition in Africa. The tournament is organised by the Confederation of African Football (CAF) and was first hosted in 1957 with four countries competing: Egypt, Sudan, Ethiopia and South Africa. The latter was disqualified due to its apartheid policy of racial discrimination. Since 1968, the competition has been held every two years. The number of participating teams which was eight in 1986 rose to 12 in 1992. In 1996, the number of teams increased from 12 to 16 with the return of South Africa into African soccer (CAF, 2014). In spite of five decades of the AFCON tournament's organisation, there remains limited information on the key performance indicators that determine team success in Africa.

Performance indicators (e.g., shots on target, ball possession, corners, accurate passes, etc.) are described as a selection or combination of action variables that aim to define some or all aspects of performance that could lead to a successful outcome (Hughes and Bartlett, 2002; Maszczyk et al., 2014). These indicators provide insight into the tactical and technical requirements of modern-day sport ( $\mathrm{O}^{\prime}$ Donoghue, 2013). Consequently, coaches use performance profiling to examine the success of an individual, a team or elements of a team (Hughes and Bartlett, 2002). Performance indicators are also used to make rational tactical decisions, build the best strategy, and improve team performance (Csataljay et al., 2009). This probably accounts for the increasing research tendency in the area of performance analysis in soccer, especially in Europe (Shafizadeh et al., 2013).

For example, in a study conducted on the Spanish La Liga competition by Lago-Ballesteros

1 - Department of Sport, Rehabilitation and Dental Sciences, Tshwane University of Technology, South Africa. 
and Lago-Peñas (2010), it was found that top teams had more assists, ball possession, total shots, and shots on target than the bottom teams in the log. In another study by Lago-Peñas et al. (2011), the number of crosses and shots on target, as well as a high percentage of ball possession, were reported as discriminative performance indicators of winning teams. Regardless of the aforementioned studies having shown similar findings in relation to successful performance indicators in soccer, there is no compelling evidence to substantiate these results within the African context. Therefore, the question that arises from this study is which performance indicators distinguish between losing and winning teams in the AFCON soccer championship?

In order to address this question, research investigations in the area of performance analysis of the AFCON tournament are needed due to the fact that it is now the world's third most lucrative soccer competition in terms of its cumulative television audience, coming after the FIFA World Cup and the UEFA Euro tournaments (CAF, 2014). This study will also add to the body of knowledge in Africa because of factors such as ground conditions, weather conditions, the referee, and tactics employed, which play a crucial role in variability of certain performance indicators (Duthie et al., 2003). Furthermore, it is generally agreed that teams from Africa adopt different playing styles compared to those of other confederations (e.g., UEFA Euro, CONCACAF and COMEBOL) (Wong, 2008). The results of this study may provide soccer coaches and analysts with valuable information to design and implement training programmes in view of the dynamic demands of the game, which can be harnessed to improve players' performance and overall team success. Therefore, the purpose this study was to examine the match performance indicators that differentiated between winning, drawing and losing teams at the 2017 AFCON soccer championships and its implications for soccer coaching and performance.

\section{Methods}

\section{Match sample}

A total sample of 32 matches played during the 2017 Total AFCON soccer championship held in Gabon was analysed. The tournament consisted of 16 teams and initially started with 24 group-stage matches, followed by four quarter-final matches, two semi-final matches, one losers' final for the third position, and a final match for the championship. Data were obtained from InStat ${ }^{\circledR}$, a private company which provides teams' physical, technical and tactical performance assessments worldwide. All matches were captured using a multiple-camera analysis system. The reliability of the data was examined using intra-rater agreement through the percentage-error method recommended by Hughes et al. (2004). This method suggests that matches must be analysed twice, with a break between the two analyses to avoid any possible adverse memory and learning effects (Sgrò et al., 2017). Therefore, for the purpose of the present study, five matches were randomly selected and observed twice within a one-week period. Consequently, all variables were found to be satisfactory, as the percentage error was less than 5\% (Hughes et al., 2004).

\section{Procedures}

Prior to data collection, ethical approval for the study was obtained from the Faculty of Science Research Ethics Committee of the Tshwane University of Technology, Pretoria, South Africa. The following performance indicators were gathered: the number of goals scored, the time period in which a goal was scored, the impact of the first goal on the match outcome, total shots, shots on goal, total passes, accurate passes, corners, ball possession, fouls, offsides, yellow cards and red cards. Additionally, the number of goals scored was recorded per 15min interval (i.e. 1-15, 16-30, 31-45, 45-60, 61-75, 76-90) and also extra time. Such performance indicators have been used to distinguish between successful and unsuccessful teams in previous research (Abdel-Hakim, 2014).

\section{Statistical analysis}

Descriptive statistics such as means, standard deviations, frequencies, and percentages were used to analyse the data. Prior to conducting parametric statistical tests, the normality of data was checked. Thus, a one-way repeated measures analysis of variance was applied to assess significant differences between losing, drawing and winning teams concerning the performance indicators of goals scored. Where the F-ratio was significant at $p<0.05$, a Tukey HSD post-hoc test was carried out for further analysis. Statistical 
analyses were performed using the Statistical Package for the Social Sciences (SPSS), version 23 (SPSS Inc., Chicago, IL, USA).

\section{Results}

Sixty-six goals were scored with an average of 2.06 per match. Figure 1 shows the time intervals in which goals were scored. Most goals were scored during the second half of the game, particularly during the $61-75-\mathrm{min}(21.2 \%)$ period. The fewest goals scored were recorded during the 31-45-min period $(9.1 \%)$ and the $46-$ 60 -min period $(12.1 \%)$. No goals were scored in the additional time of the first half. However, five goals were scored during the additional time of the second half and extra time. No significant ( $p>$ 0.05 ) differences were noted in the frequency of goals scored.

Figure 2 presents the impact of the first goal scored on the match outcome. The results showed that the team that scored the first goal won in $17(60.7 \%)$ matches, drew eight (28.6\%) matches, and lost only three (10.7\%) matches. Four games ended without goals being scored. No significant $(p>0.05)$ differences were observed in the impact of the first goal scored in relation to the match outcome.

Table 1 shows the game-related statistics for losing, drawing, and winning teams. Winning teams had higher mean values of the following variables: goals scored $(1.80 \pm 0.83)$, total shots $(11.05 \pm 4.83)$, shots on target $(4.70 \pm 2.62)$, fouls $(18.60 \pm 5.19)$, offsides $(2.35 \pm 1.76)$, yellow cards $(1.55 \pm 1.10)$, and red cards $(0.05 \pm 0.22)$. In contrast, losing teams yielded higher mean values in total passes $(260.30 \pm 49.10)$, accurate passes $(69.28 \pm 5.74)$, corners $(5.10 \pm 2.95)$, and ball possession (51.20 \pm 5.52$)$. A significant difference was observed between losing, drawing and winning teams concerning the number of goals scored $(F[2,61]=18.12, p=0.00)$. The Tukey HSD post-hoc test indicated that the mean value of the goals scored by winning teams was significantly different from that of losing and drawing teams.

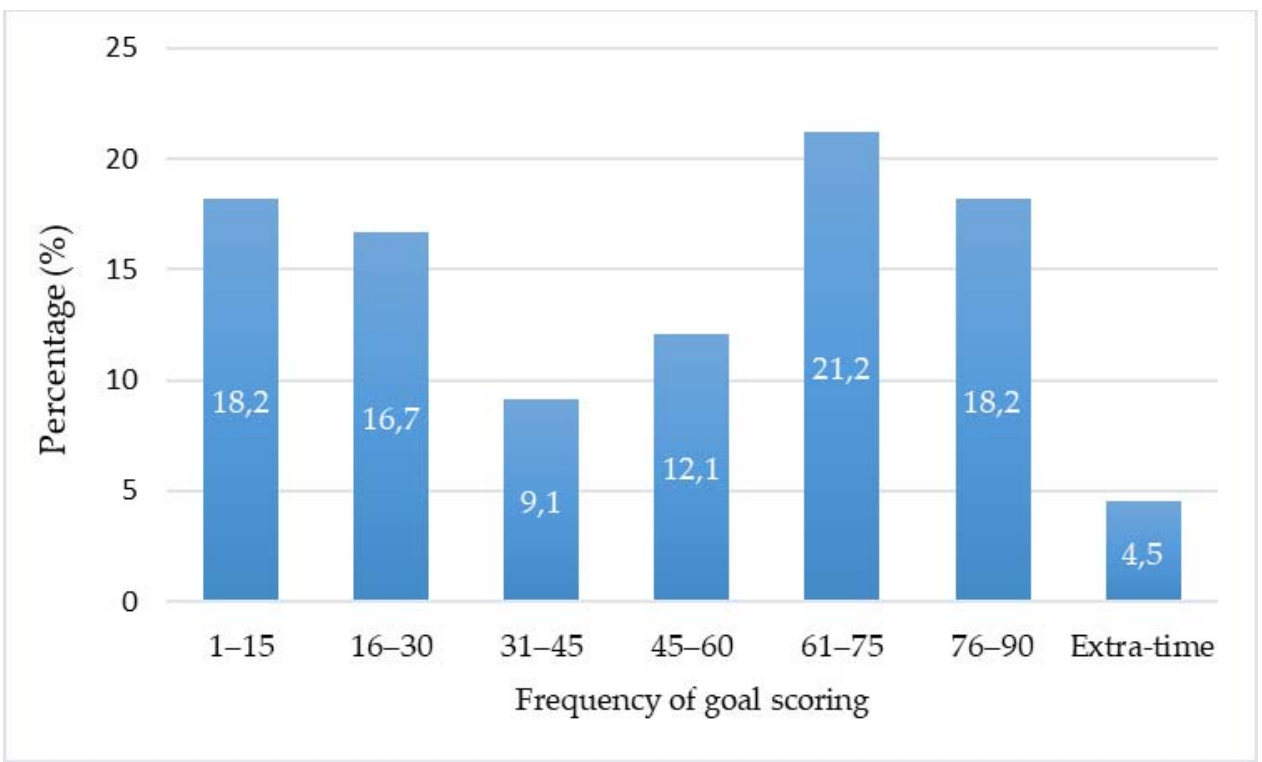

Figure 1

Timing of goals scored during the 2017 AFCON 




Figure 2

First goal scored and the game outcome

Table 1

Differences between winning, drawing and losing teams according to match statistics

\begin{tabular}{lccccc}
\hline Variable & $\begin{array}{c}\text { Losing } \\
(\mathrm{n}=20)\end{array}$ & $\begin{array}{c}\text { Drawing } \\
(\mathrm{n}=24)\end{array}$ & $\begin{array}{c}\text { Winning } \\
(\mathrm{n}=20)\end{array}$ & $\begin{array}{c}\text { All } \\
(\mathrm{N}=64)\end{array}$ & $p$ \\
\hline Goals scored & $0.40 \pm 0.60$ & $0.92 \pm 0.78$ & $1.80 \pm 0.83$ & $1.03 \pm 0.93$ & $0.00^{*}$ \\
Total shots & $10.55 \pm 4.39$ & $11.33 \pm 4.87$ & $11.05 \pm 4.83$ & $11.00 \pm 4.65$ & 0.86 \\
Shots on target & $3.80 \pm 1.76$ & $4.67 \pm 2.50$ & $4.70 \pm 2.62$ & $4.41 \pm 2.33$ & 0.38 \\
Total passes & $260.30 \pm 49.10$ & $266.67 \pm 83.82$ & $258.80 \pm 54.62$ & $262.22 \pm 64.84$ & 0.91 \\
Accurate & $69.28 \pm 5.74$ & $69.13 \pm 8.13$ & $69.10 \pm 6.50$ & $69.17 \pm 6.84$ & 0.99 \\
(\%) & $5.10 \pm 2.95$ & $5.13 \pm 2.92$ & $3.35 \pm 2.81$ & $4.56 \pm 2.97$ & 0.09 \\
Corners & $51.20 \pm 5.52$ & $50.00 \pm 5.70$ & $48.80 \pm 5.52$ & $50.00 \pm 5.58$ & 0.40 \\
Foull possession $(\%)$ & $17.45 \pm 4.36$ & $19.67 \pm 6.32$ & $18.60 \pm 5.19$ & $18.64 \pm 5.41$ & 0.41 \\
Offside & $1.60 \pm 1.43$ & $1.71 \pm 1.46$ & $2.35 \pm 1.76$ & $1.88 \pm 1.56$ & 0.26 \\
Yellow cards & $1.15 \pm 1.04$ & $1.21 \pm 1.10$ & $1.55 \pm 1.10$ & $1.30 \pm 1.08$ & 0.45 \\
Red card & $0.00 \pm 0.00$ & $0.00 \pm 0.00$ & $0.05 \pm 0.22$ & $0.02 \pm 0.13$ & 0.34 \\
\hline
\end{tabular}

*Significant at $p<0.05$ 


\section{Discussion}

This study analysed performance indicators that discriminated between drawing, winning and losing teams during the 2017 Total AFCON soccer tournament in relation to team success. It was found that 66 goals were scored with an average of 2.06 goals per match. The average number of goals scored was relatively low compared to the averages of previous studies of the UEFA Championships that varied between 2.48 in 2008 and 2.45 in 2012 (Mitrotasios and Armatas, 2014; UEFA, 2016). However, a low scoring rate in African soccer could be explained by the so-called 'parking the bus' tactics phenomenon (The Football Supernova, 2012), which signifies a characteristically defensive style of play. The advancement of modern technology regarding match-data analysis, such as those by Prozone and InStat in Africa, could provide teams with information needed to scout opponents and devise appropriate strategies. Likewise, a coach analysing opposition performance will use data to counter opponents' strengths and exploit their weaknesses (Carling et al., 2005).

The results further showed that most goals were scored between the $61^{\text {st }}$ and $75^{\text {th }}$ minutes of the game. This is an interesting finding considering the fact that previous research (Njororai, 2013) found that most of the goals were scored towards the last 15-min period of the match. This new important finding implies that teams can score goals at any time in order to settle in and avoid rushing towards the end of the game. The results also found that the majority $(60.7 \%)$ of teams that scored the first goal went on to win their games. This finding supports that of Michailidis (2014), who also reported that $75.4 \%$ of the teams that scored the first goal during the 2014 FIFA World Cup won their games. This result suggests that teams that score the first goal tend to gain confidence, which, in turn, may give them the advantage of not conceding goals and thus improving their chances of winning. Equally, taking a lead as early as possible could help teams to avoid chasing a result (i.e., draw or win) towards the end of the match before fatigue sets in (Reilly, 1997).

Winning teams had more shots and shots on target than losing and drawing teams. These findings corroborate those of Lago-Peñas et al. (2010). Also, Szwarc (2004) found that finalist teams made more shots than unsuccessful teams during the 2002 FIFA World Cup in Korea/Japan. Similar results have been reported by Armatas et al. (2009), who found that top teams made more shots compared to the bottom teams in the Greek First Division. The results of this study indicated that winning teams scored significantly more goals than losing and drawing teams. Therefore, it could be concluded that teams that take more shots on target have more goal-scoring opportunities, which may increase their chances of winning matches. Consistent with a view expressed by Lago-Peñas et al. (2010), the findings of the present study support the assertion that winning teams perform better in the factors associated with goals scored (e.g., shots on target, etc.) in contrast to losing and drawing teams.

The low percentage of ball possession among winning teams in this study is quite surprising given that winning teams were anticipated to have higher ball possession than losing teams. This finding contradicts that of Lago-Peñas and Dellal (2010), who found that successful teams had a high percentage of ball possession compared to losing teams. Perhaps this could be explained by the fact that losing teams tend to create more goal-scoring opportunities in order to draw or win the match, which requires greater ball possession (Lago and Martín, 2007). Likewise, in another study of the UEFA Champions League, Lago-Peñas et al. (2011) found that winning teams maintained longer ball possession than unsuccessful teams. However, caution should be exercised in comparing the percentages of ball possession across studies conducted in different settings. Differences in the style of play between teams may explain the reported findings. Compared to previous research (Lago-Peñas et al., 2011) reporting that winning teams had more total and accurate passes, this study demonstrates that losing teams had more accurate passes. Although it was not ascertained in the present study, it could be speculated that such teams were passing the ball laterally, which is not effective in advancing forward in order to create more goalscoring opportunities.

\section{Conclusion}

This study examined performance indicators of goals scored during the 2017 Total AFCON soccer competition. It was found that 
most goals were scored during the second half of the game, particularly during the 61-75-min $(21.2 \%)$ period. The results further indicated that winning teams had more goals, total shots, and shots on target than drawing and losing teams. Finally, most of the teams that had a high percentage of ball possession lost their games.

\section{Practical implications}

The present study provides novel data for soccer coaches which should be taken into consideration when preparing team tactics. It is recommended that coaches should design training programmes in order to improve players' abilities to take shots on target. Such training sessions should also be incorporated in the pre-match warm-ups. Soccer coaches and analysts should tailor their match tactics such that they employ a direct play or counter attack approach. This was evident in the results of the current study which showed that winning teams had a lower percentage of ball possession than losing teams.

\section{References}

Abdel-Hakim HH. Quantitative analysis of performance indicators of goals scored in the Futsal World Cup Thailand 2012. Pamukkale J Sport Sci, 2014; 5(1): 113-127

Armatas V, Yiannakos A, Zaggelidis G, Papadopoulou S, Fragkos N. Goal scoring patterns in Greek top leveled soccer matches. J Phys Educ Sport, 2009; 23(2): 1-5

Confederation of African Football (CAF). The history of AFCON. 2014. Available at http://www.caf.com . Accessed on 2 January 2017

Carling C, Williams A, Reilly T. The handbook of soccer match analysis: A systematic approach to improving performance. London: Routledge; 2005

Csataljay G, O'Donoghue P, Hughes M, Dancs H. Performance indicators that distinguish winning and losing teams in basketball. Int J Perf Anal Sport, 2009; 9: 60-66

Duthie G, Pyne D, Hooper S. Applied physiology and game analysis of rugby union. Sports Med, 2003; 33: 973-991

Hughes MD, Bartlett RM. The use of performance indicators in performance analysis. J Sport Sci, 2002; 20(10): 739-754

Hughes M, Cooper SM, Nevill A. Analysis of notation data: Reliability. In M. Hughes \& I. M. Franks (Eds.), Notational analysis of sport (2nd ed., pp. 189-204). London, New York, NY: Routledge; 2004

Lago C, Martín R. Determinants of possession of the ball in soccer. J Sport Sci, 2007; 25(9): 969-974

Lago-Ballesteros J, Lago-Peñas C. Performance in team sports: Identifying the keys to success in soccer. J Hum Kinet, 2010; 25, 85-91

Lago-Peñas C, Dellal A. Ball possession strategies in elite soccer according to the evolution of the matchscore: the influence of situational variables. J Hum Kinet, 2010; 25: 93-100

Lago-Peñas C, Lago-Ballesteros J, Dellal A, Gómez M. Game-related statistics that discriminated winning, drawing and losing teams from the Spanish soccer league. J Sport Sci Med, 2010; 9: 288-293.

Lago-Peñas C, Lago-Ballesteros J, Rey E. Differences in performance indicators between winning and losing teams in the UEFA Champions league. J Hum Kinet, 2011; 27: 137-148

Maszczyk A, Gołaś A, Pietraszewski P, Roczniok R, Zając A, Stanula A. Application of Neural and Regression Models in Sports Results Prediction. Procedia - Soci Behavio Sci, 2014; 117: 482-487

Michailidis Y. Analysis of goals scored in the 2014 World Cup soccer tournament held in Brazil. Int J Sport Stud, 2014; 4(9): 1017-1026

Mitrotasios M, Armatas V. Analysis of Goal Scoring Patterns in the 2012 European Football Championship. The Sport J, 2004; $1-8$

Njororai WWS. Analysis of goals scored in the 2010 World Cup soccer tournament held in South Africa. J Phys Educ Sport, 2013; 13(1): 6-13

O'Donoghue P. Sports performance profiling. In T. McGarry, P. O'Donoghue, \& J. Sampaio (Eds.), Routledge handbook of sports performance analysis (pp. 127-139). Abingdon: Routledge, 2013 
Reilly T. Energetics of high intensity exercise (soccer) with particular reference to fatigue. J Sports Sci, 1997; 15: 257-263

Sgrò F, Aiello F, Casella A, Lipoma M. The effects of match-playing aspects and situational variables on achieving score-box possessions in Euro 2012 Football Championship. J Hum Sport Exerc, 2017; 12(1): 58-72.

Shafizadeh M, Taylor M, Lago-Peñas C. Performance consistency of international soccer teams in Euro 2012: a time series analysis. J Hum Kinet, 2013; 38: 213-225

Szwarc A. Effectiveness of Brazilian and German teams and the teams defeated by them during the 17th Fifa World Cup. Kinesiol, 2004; 36(1): 83-89

The Football Supernova. The myth of 'parking the bus'. 2012. Accessed on 14 August 2017.

UEFA.com. (2016). How the 108 goals at UEFA EURO 2016 went in. Available at http://www.uefa.com/uefaeuro/news/newsid=2387449.html. Accessed on 20 May 2017

Wong D. Characteristics of world cup soccer players. Soccer J, 2008; 53: 57-62

\section{Corresponding author:}

\section{Alliance Kubayi}

Tshwane University of Technology

Department of Sport, Rehabilitation and Dental Sciences

Republic of South Africa; Pretoria; 0001

Telephone number: +27 123824272

Fax number: +27 123825801

Email address: kubayina@tut.ac.za 